\title{
Update on Microbicide Research ANd DeVelopment - SeEking NeW HIV Prevention Tools for Women
}

\author{
T. Mertenskoetter, P. E. Kaptur
}

International Partnership for Microbicides, Silver Spring, MD, USA

\begin{abstract}
Women and girls are especially vulnerable to HIV infection in sub-Saharan Africa, and in some of those countries, prevalence among young women can be up to 3 times higher than among men of the same age. Effective HIV prevention options for women are clearly needed in this setting. Several ARV-based vaginal microbicides are currently in development for prevention of HIV transmission to women and are discussed here. The concept of pre-exposure prophylaxis for the prevention of HIV transmission to women is introduced.
\end{abstract}

Key words: microbicides, HIV prevention, pre-exposure prophylaxis (PrEP), antiretrovirals, vaginal gel, vaginal ring

\section{Abbreviations:}

ARV $=$ Antiretroviral (drug)

ATN $=$ Adolescent Medicine Trials Network

BMGF $=$ Bill \& Melinda Gates Foundation

CAPRISA $=$ Centre for the AIDS Programme of Research in South Africa

EMA = European Medicines Agency

FDA $=$ U.S. Food and Drug Administration

$\mathrm{FHI}=$ Family Health International

FTC $=$ Emtricitabine

HEC $=$ Hydroxyethyl cellulose

IAVI = International AIDS Vaccine Initiative

IPM = International Partnership for Microbicides

MTN $=$ Microbicide Trials Network

NIAID $=$ National Institute of Allergy and Infectious Diseases

NICHD $=$ National Institute of Child Health \& Human Development

NNRTI = Non-nucleoside reverse transcriptase inhibitor

NRTI $=$ Nucleoside reverse transcriptase inhibitor

PrEP $=$ Pre-exposure prophylaxis

TDF $=$ Tenofovir disoproxil fumerate

USAID = United States Agency for International Development

VOICE = Vaginal and Oral Interventions to Control the Epidemic (trial)

\section{INTRODUCTION}

Current HIV incidence rates in highly impacted regions reflect the magnitude of the epidemic and point out an apparent lack of HIV prevention methods, specifically for women. Sixty-eight percent of the 2.3 million adults newly infected with HIV in 2008 live in sub-Saharan Africa, where approximately $60 \%$ of infected individuals are women [1]. Women and adolescent girls are especially vulnerable to HIV infection in sub-Saharan Africa not only because of their increased physiological susceptibility to heterosexual transmission, but also because of social, legal, and economic disadvantages [1]. According to the most recent estimate, the number of people living with HIV is 33.4 million [1]. In the nine countries in southern Africa affected most by HIV (Botswana, Lesotho, Malawi, Mozambique, Namibia, South Africa, Swaziland, Zambia, and Zimbabwe), prevalence among young women aged 15-24 years was reported to be approximately 3 times higher than among men of the same age [2]. HIV prevention options for women are presently limited in this setting.

Microbicides to prevent HIV infection in women are vaginally applied topical products that interfere with HIV infection at one or more steps in the replication cycle. This paper summarizes research to date on early generation product development efforts (polyanions, surfactants, acidifying agents) and next generation antiretroviral (ARV)-based HIV microbicides and introduces the concept of pre-exposure prophylaxis (PrEP) for the prevention of HIV transmission.

\section{The NeEd for a Female-Initiated HIV Prevention Method}

Half of the exposed population currently has no effective means of self-initiated HIV prevention; and although condoms provide good protection from HIV infection, their regular use is not always negotiable by women. The effectiveness of an HIV prevention method is impacted by its correct and consistent use. Therefore, microbicide research and development has also focused on the topic of adherence, and factors affecting adherence, such as preferred dosage forms and regimens, stigma associated with microbicide use, male perception of microbicide use, and various dosage forms and regimens.

An ideal microbicide product would be highly effective against HIV transmission and potentially other pathogens, have a very good safety profile, create no drug-drug interactions with other vaginal products, and could be easily and discreetly used on a regular ba- 
sis. The half-life of the active pharmaceutical ingredient ideally would be long enough so that protective drug levels would be maintained in tissues even with lapses in product use. Dosing regimens should accommodate the range in female sexual behavior from regular intercourse to periods of abstinence. Long-acting dosage forms such as vaginal rings may be an attractive feature for women as well as improve adherence and therefore the effectiveness of the product. Product formulations that combine HIV prevention with contraception are in early stages of development and would offer women additional options [3].

\section{OVERVIEW OF RESEARCH AND DEVELOPMENT EFFORTS WITH NON-ARV-BASED MICROBICIDES}

Several early generation microbicide gels were evaluated for efficacy in phase IIb and phase III trials with disappointing results. These include the surfactants nonoxynol-9 [4] and SAVVY (Cellegy Pharmaceuticals, Huntington Valley, PA, USA) [5]; three polyanions, cellulose sulfate [6], Carraguard ${ }^{\circledR}$ (Population Council, New York, NY, USA) [7], and PRO 2000 (Endo Pharmaceuticals, Chadds Ford, PA, USA) [8]; and an acidifying agent, BufferGel (ReProtect LLC, Baltimore, MD, USA) [8]. None proved to inhibit HIV infection, and in fact with three of the gels, nonoxynol-9, cellulose sulfate, and SAVVY, a trend toward increased risk of HIV infection was observed [4$6]$.

\section{OVERVIEW OF RESEARCH AND DEVELOPMENTS EFFORTS WITH ARV-BASED MiCROBICIDES}

Microbicide research has now shifted to development of next-generation, ARV-based formulations in multiple dosage forms such as vaginal gels, rings, films, soft-gel capsules, and tablets [9-11]. Formulations of ARVs that target reverse transcriptase are furthest along in development as topical microbicides (Table 1). Proof-of-concept was shown recently with a vaginal gel containing tenofovir, an NRTI.

\section{TENOFOVIR}

In July 2010, positive results were reported from the CAPRISA 004 trial in South Africa [12]. When com- pared with the HEC-based universal placebo gel, 1\% tenofovir gel was 39\% effective (incidence rate ratio $0.61, p=0.017)$ at reducing new HIV infection after 30 months of coitally-dependent use by sexually-active women aged 18 to 40 years. The effectiveness increased to $54 \%(p=0.025)$ when only data for women who used the gel correctly were analyzed. The protective effect of tenofovir gel was evident at 6 months, $50 \%$ at 12 months ( $p=0.007$ ), and was $40 \%$ at 24 months $(p=0.013)$. Tenofovir gel had a favorable safety profile: only diarrhea and gastrointestinal infections were significantly higher in the tenofovir gel vs. placebo gel group (17\% vs. $11 \%, \mathrm{p}=0.02)$.

An ongoing study (MTN 003, also referred to as the "Vaginal and Oral Interventions to Control the Epidemic" or "VOICE" trial) funded by NIAID and sponsored by the Microbicide Trials Network is being conducted in Africa (Malawi, South Africa, Uganda, Zimbabwe) to test the effectiveness of daily $1 \%$ tenofovir gel vs. placebo gel as well as the effectiveness of oral tenofovir disoproxil fumarate $\left(\right.$ Viread $^{\circledR}$, Gilead Sciences, Foster City, CA, USA) and oral emtricitabine/tenofovir disoproxil fumarate (Truvada ${ }^{\circledR}$, Gilead Sciences) vs. oral placebo measured by HIV seroconversion. Extended safety of the products in women at risk for sexually transmitted HIV infection will also be assessed. The results of this study may answer the question whether daily dosing (used in the VOICE trial) improves adherence and effectiveness of tenofovir gel compared with coitally-associated dosing (used in the CAPRISA trial) without compromising the safety profile. The results of the VOICE trial are expected in 2013.

\section{DAPIVIRINE}

Dapivirine, an NNRTI initially developed by Tibotec Pharmaceuticals in Belgium, has been tested for safety in sexually active, HIV-negative women in both vaginal gel (daily dosing) and vaginal ring (monthly dosing) formulations. Both dosage forms have been shown to have similar safety profiles to their respective placebos and to release dapivirine into the lower female genital tract at concentrations well above those shown to be protective in vitro and ex vivo, and well above concentrations in plasma that have been shown to reduce viral load [13-19]. Two more recently developed formulations of $0.05 \%$ dapivirine gel have been tested in

Table 1. ARV-Based Microbicides Products in Development.

\begin{tabular}{llll}
\hline Product & MOA & License Holder(s) & Phase of Development \\
\hline Tenofovir gel & NRTI & CONRAD and IPM & Phase IIB \\
Dapivirine gel and ring & NNRTI & IPM & Phase I/II \\
Dapivirine-maraviroc combination gel and ring & NNRTI + CCR5 blocker & IPM & Phase I planned \\
Maraviroc ring and gel & CCR5 blocker & IPM & Phase I planned \\
Maraviroc-tenofovir combination film & CCR5 blocker + NRTI & IPM & Late preclinical \\
MIV-150 gel and ring & NNRTI & Population Council & Late preclinical \\
\hline
\end{tabular}


safety studies in Kenya, Malawi, Rwanda, South Africa, and the United States. A safety study with the current dapivirine ring formulation (25 $\mathrm{mg})$ is ongoing in South Africa, Kenya, and Malawi, and two pharmacokinetics studies with the ring were recently completed in Belgium.

\section{MARAVIROC}

Maraviroc, a CCR 5 co-receptor antagonist marketed as Selzentry ${ }^{\circledR}$ (Pfizer Labs, New York, NY, USA) for treatment of CCR5-tropic HIV-1 infection, is in development as a vaginal microbicide [20]. Vaginal gels and rings containing a combination of dapivirine plus maraviroc are in development; phase I clinical trials are planned for 2011. These products have the potential advantage of blocking HIV infection at two different steps in the replication cycle, attachment and reverse transcription. Vaginal gels and rings containing maraviroc as a single agent are in development in parallel with the combination dosage forms and will be included in the phase I clinical trials planned for 2011. In addition, a combination vaginal film with maraviroc and tenofovir is in preclinical development.

\section{MIV-150}

MIV-150 is an NNRTI with potent activity against HIV-1 and HIV-2, including free HIV-1 and HIV-1 strains that are resistant to other ARVs [21-22]. MIV150 is currently under development at Population Council in both microbicide gel (PC-815 and PC1005) and ring formulations [23-25]. Population Council researchers are also developing vaginal rings that contain both MIV-150 and a contraceptive to protect women against both HIV infection and pregnancy.

\section{Challenges FaCed in Microbicide DEVELOPMENT}

The establishment of surrogate markers for determination of clinical efficacy and survival-enhancing effects of ARVs (rises in CD4 cell counts and decreases in HIV viral load) dramatically enhanced the development of new medicines for the treatment of HIV infection [26, 27]. To date, no surrogate markers have been identified for measurement of the efficacy of HIV prevention tools; therefore, microbicide clinical trials are designed to measure the difference in infection rates between the active and control groups. For this reason, trial settings must have sufficiently high HIV incidence rates (typically over $2 \%$ ) to show a significant reduction with the intervention. Furthermore, careful selection of microbicide candidates to test in clinical trials is imperative because of shared trial sites and high trial expenses. Because of the lack of surrogate markers, in vitro assays, cervical explant models, and animal models have been utilized to estimate the potential for preventive efficacy of new microbicide compounds in women. These models are experimental and have not been validated. The development of pharmacokinetic/pharmacodynamic models is being explored [28] and ideally would be able to predict the pharmacodynamic effect of a microbicide candidate from the pharmacokinetic profile.

Adherence with the microbicide regimen is generally measured in clinical trials by self-reported product use and counting of returned used and unused gel applicators [29]. This provides only an estimate of true adherence and no information on the time of product insertion. Others have explored "daily monitored adherence" and found that daily contact with trial participants can improve adherence to the microbicide regimen [30].

Use of ARV-based vaginal microbicides could potentially induce drug resistance in individuals who are unaware that they are HIV infected if subtherapeutic drug levels consistent with the selection of resistance in vivo are attained. Systemic drug exposure after vaginal dosing with NRTI- and NNRTI-based microbicides has been shown to be low $[13,14,16,17,18,31$, 32], while concentrations in cervicovaginal fluids have been shown to be many logs greater than in vitro concentrations at which resistance mutations were noted [13]. Combination microbicides with two drugs that target different steps in the HIV replication cycle may reduce the potential for development of HIV resistance by increasing the barrier to infection [28, 33]. Furthermore, combination microbicides may help prevent the transmission of virus resistant to a specific drug via the mechanism of action of the other drug in the combination. Development of resistance is being studied in the clinical context through the implementation of seroconvertor protocols [12, 13]. The monitoring of microbicide users for HIV infection is therefore important, and recommended timetables for HIV testing are under development. Monthly HIV testing is generally used in microbicide trials; however, this schedule may not be feasible after product approval.

\section{Priorities in Microbicide Development}

Now that proof-of-concept for an ARV-based vaginal microbicide has been established through the successful completion of the CAPRISA trial [12], interest in new HIV prevention tools has received a boost. It is now a priority to set-up the necessary confirmatory and supporting studies for the continued clinical development of tenofovir gel, which could then lead to the approval and launch of the first ARV-based microbicide. Other ARV-based microbicides that hold promise for increasing potency and addressing product adherence concerns need to be prioritized for development, including products ready for efficacy testing such as the dapivirine-containing vaginal ring.

Optimizing implementation programs and measuring the real-life public health impact will be further milestones. Establishment of a comprehensive postapproval drug safety surveillance system is important when microbicides are introduced into the markets in developing countries because there is no experience with the use of these products in regions under the jurisdiction of the FDA or EMA. Also, since these products will be used by otherwise healthy women, monitoring product safety is paramount. Further development of ARV-based microbicides (including 


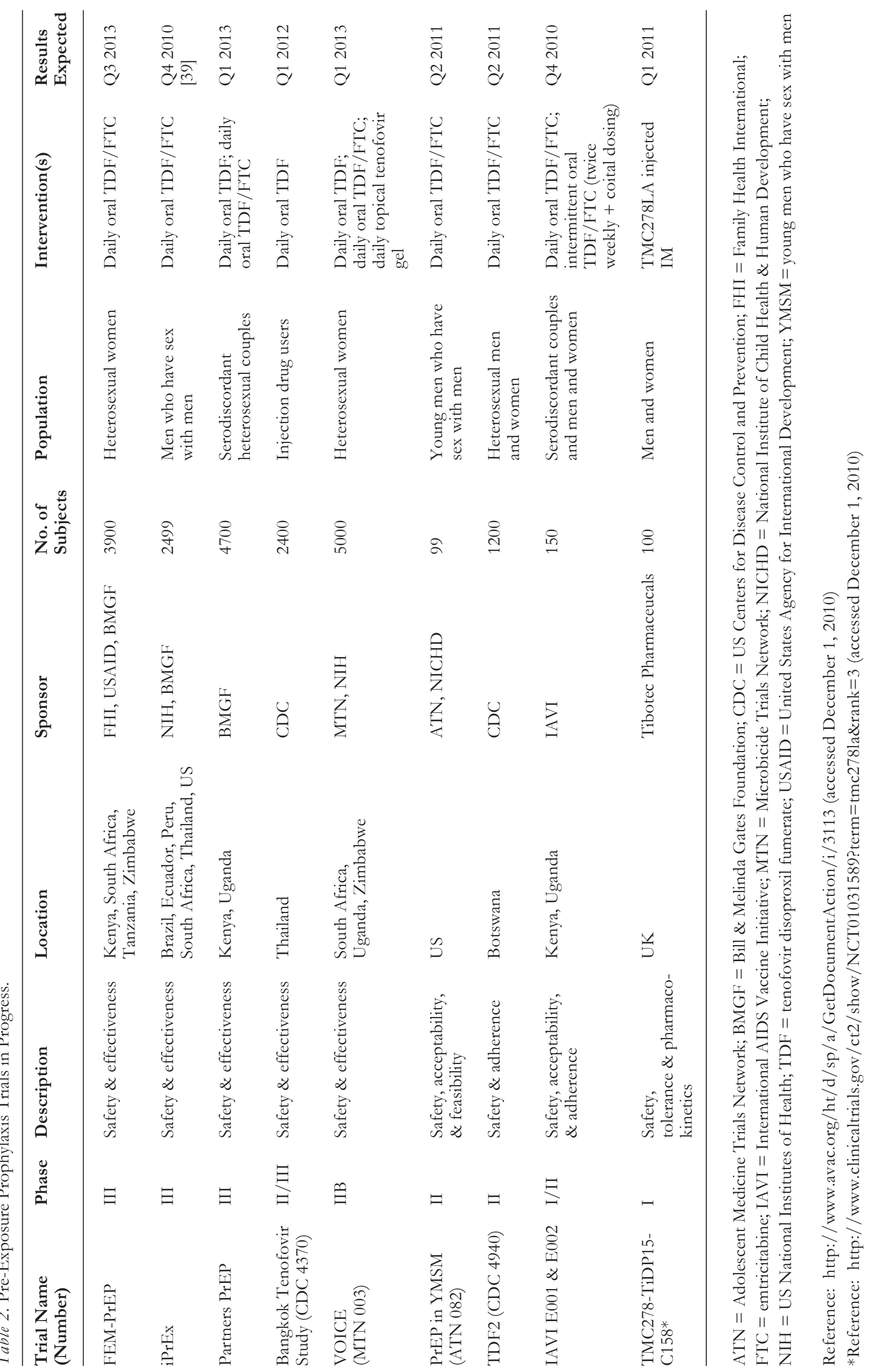


drug combinations) with longer-acting formulations and in multiple dosage forms remains a priority to offer women choices, a strategy that has proven to be very successful in the field of contraception $[34,35]$.

\section{Pre-Exposure Prophylaxis (PrEP)}

In addition to HIV microbicide development, oral PrEP of HIV infection with ARV drugs approved for treatment of HIV and AIDS is currently under investigation [36-39]. The VOICE trial described above is one such trial. Other PrEP trials being conducted worldwide are shown in Table 2. All but one of these trials is with oral tenofovir disoproxil fumarate and/or oral emtricitabine plus tenofovir disoproxil fumarate. Intramuscular injection of TMC278LA, an NNRTI for HIV prevention, is presently being tested in a phase I trial in the UK. The results of the first oral PrEP trials in women are expected in 2010 and 2011.

The findings of these PrEP trials should hopefully demonstrate the efficacy, safety, and tolerability of ARVs in HIV-negative individuals. In addition, the results will be used to develop public health guidelines for prevention of HIV transmission in different populations such as heterosexual couples, serodiscordant couples, men who have sex with men, and injection drug users. If proven safe and effective, PrEP could help address the urgent need for a female-initiated prevention method for women worldwide.

\section{CONCLUSIONS}

There is an immediate need for female-initiated HIV prevention tools. Microbicide research, like most HIV prevention research, has faced many hurdles over the past two decades, but proof-of-concept in the CAPRISA trial has reignited the hope of obtaining safe and effective HIV microbicides that are acceptable to the women who will use these products. Several ARV-based microbicides are in clinical trials at this time, and many others are in preclinical stages of development. Oral PrEP with ARVs approved for treatment of HIV/AIDS is currently under investigation with the first trial results expected in 2010 and 2011.

\section{REFERENCES}

1. AIDS epidemic update 2009. Joint United Nations Programme on HIV/AIDS (UNAIDS) and World Health Organization (WHO) 2009. UNAIDS/09.36E/JC1700E, November 2009.

2. Gouws E, Stanecki KA, Lyerla R, Ghys PD. The epidemiology of HIV infection among young people aged 15-24 years in southern Africa. AIDS. 2008 Dec; 22 Suppl 4: S5-16.

3. Chandran P, Kabir SN. Dual action microbicides: reappraisal of their roles in contraceptive research. Reprod Biomed Online. 2010 Jan; 20(1): 103-13.

4. Van Damme L, Ramjee G, Alary M, Vuylsteke B, Chandeying V, Rees $\mathrm{H}$, Sirivongrangson P, MukengeTshibaka L, Ettiègne-Traoré V, Uaheowitchai C, Karim SS, Mâsse B, Perriëns J, Laga M; COL-1492 Study Group.
Effectiveness of COL-1492, a nonoxynol-9 vaginal gel, on HIV-1 transmission in female sex workers: a randomised controlled trial. Lancet. 2002 Sep 28; 360(9338): 971-7.

5. Feldblum PJ, Adeiga A, Bakare R, Wevill S, Lendvay A, Obadaki F, Olayemi MO, Wang L, Nanda K, Rountree W. SAVVY vaginal gel (C31G) for prevention of HIV infection: a randomized controlled trial in Nigeria. PLoS One. 2008 Jan 23; 3(1): e1471.

6. Van Damme L, Govinden R, Mirembe FM, Guédou F, Solomon S, Becker ML, Pradeep BS, Krishnan AK, Alary M, Pande B, Ramjee G, Deese J, Crucitti T, Taylor D; CS Study Group. Lack of effectiveness of cellulose sulfate gel for the prevention of vaginal HIV transmission. N Engl J Med. 2008 Jul 31; 359(5): 463-72.

7. Skoler-Karpoff S, Ramjee G, Ahmed K, Altini L, Plagianos MG, Friedland B, Govender S, De Kock A, Cas$\operatorname{sim}$ N, Palanee T, Dozier G, Maguire R, Lahteenmaki P. Efficacy of Carraguard for prevention of HIV infection in women in South Africa: a randomised, double-blind, placebo-controlled trial. Lancet. 2008 Dec 6; 372(9654): 1977-87.

8. Morris GC, Lacey CJN. Microbicides and HIV prevention: lessons from the past, looking to the future. Curr Opin Infect Dis. 2010 Feb; 23(1): 57-63.

9. Nuttall J. Microbicides in the prevention of HIV infection: current status and future directions. Drugs. $2010 \mathrm{Jul}$ 9; 70(10): 1231-43.

10. Friend DR. Pharmaceutical development of microbicide drug products. Pharm Dev Technol. 2009 Dec 17; 1-20.

11. Romano J, Malcolm RK, Garg S, Rohan LC, Kaptur PE. Microbicide delivery: formulation technologies and strategies. Curr Opin HIV AIDS. 2008 Sep; 3(5): 558-66.

12. Karim QA, Karim SSA, Frohlich JA, Grobler AC, Baxter C, Mansoor LE, Kharsany ABM, Sibeko S, Mlisana KP, Omar Z, Gengiah TN, Maarschalk S, Arulappan N, Mlotshwa M, Morris L, Taylor D, on behalf of the CAPRISA 004 Trial Group). Effectiveness and safety of tenofovir gel, an antiretroviral microbicide, for the prevention of HIV infection in Women. Sciencexpress. 2010 Jul 19; 1-13.

13. Nel AM, Smythe SC, Habibi S, Kaptur PE, Romano JW. Pharmacokinetics of 2 dapivirine vaginal microbicide gels and their safety vs. hydroxyethyl cellulose-based universal placebo gel. J Acquir Immune Defic Syndr. 2010 Oct 1; 55(2): 161-9.

14. Nel AM, Coplan P, Smythe SC, McCord K, Mitchnick M, Kaptur PE, Romano J. Pharmacokinetic assessment of dapivirine vaginal microbicide gel in healthy, HIV-negative women. AIDS Res Hum Retroviruses. 2010 Sep 21 \{Epub ahead of print].

15. Nel A, Kamupira M, Hetro C, Nuttall J, Romano J. Safety and pharmacokinetics trial of dapivirine matrix vaginal ring. 18th International AIDS Conference, Vienna, Austria, July 18-23, 2010, \#PE0391.

16. Romano J, Variano B, Coplan P, Van Roey J, Douville K, Rosenberg Z, Temmerman M, Verstraelen H, Van Bortel L, Weyers S, Mitchnick M. Safety and availability of dapivirine (TMC120) delivered from an intravaginal ring. AIDS Res Hum Retroviruses. 2009 May; 25(5): 1-6.

17. Nel AM, Coplan P, van de Wijgert JH, Kapiga SH, von Mollendorf C, Geubbels E, Vyankandondera J, Rees HV, Masenga G, Kiwelu I, Moyes J, Smythe SC. Safety, tolerability, and systemic absorption of dapivirine vaginal microbicide gel in healthy HIV-negative women. AIDS. 2009 Jul 31; 23(12): 15318.

18. Nel A, Smythe S, Young K, Malcolm K, McCoy C, Rosenberg Z, Romano J. Safety and pharmacokinetics of dapivirine delivery from matrix and reservoir intravaginal rings to HIV-negative women. J Acquir Immune Defic Syndr. 2009 Aug 1; 51(4): 416-23. 
19. Van't Klooster G, van der Geest R, Gille D. Parmacokinetics, tolerability and safety of multiple oral doses of TMC120 (R147681) in 32 healthy subjects. Tibotec Pharmaceuticals Ltd. Trial No. TIBO-0001-104, Report No. TMC120-C104-CRR, April 9, 2004.

20. Veazey RS, Ketas TJ, Dufour J, Moroney-Rasmussen T, Green LC, Klasse PJ, Moore JP. Protection of Rhesus macaques from vaginal infection by vaginally delivered maraviroc, an inhibitor of HIV-1 entry via the CCR 5 coreceptor. J Infect Dis. 2010 Sep 1; 202(5): 739-44.

http://www.retroconference.org/2010/Abstracts/39821.htm Accessed on September 28, 2010.

21. Turville SG, Aravantinou M, Miller T, Kenney J, Teitelbaum A, Hu L, Chudolij A, Zydowsky TM, Piatak M Jr, Bess JW Jr, Lifson JD, Blanchard J, Gettie A, Robbiani M. Efficacy of Carraguard ${ }^{\circledR}$-based microbicides in vivo despite variable in vitro activity. PLoS One. 2008 Sep 8; 3(9): e3162.

22. Fernandez-Romero JA, Thorn M, Turville SG, Titchen K, Sudol KM, Li J, Miller T, Robbiani M, Maguire RA, Buckheit RW Jr, Hartman TL, Phillips DM. Carrageenan/MIV-150 (PC-815), a combination microbicide. Sex Transm Dis 2007 Jan; 34(1): 9-14.

23. Nonclinical Laboratory Studies: PC-1005 Gel (Carrageenan with Added MIV-150 and Zinc Salts). Population Council website.

http://www.popcouncil.org/projects/285_NonclinLab PC1005.asp. Accessed on September 27, 2010.

24. Nonclinical Laboratory Studies: Vaginal Rings Loaded with MIV-150. Population Council website. http://www.popcouncil.org/projects/286_NonclinLab MIV150Ring.asp. Accessed on September 27, 2010.

25. Nonclinical Laboratory Studies: Microbicide Formulation and Delivery. Population Council website. http://www.popcouncil.org/projects/285_NonclinLab PC1005.asp. Accessed on September 27, 2010.

26. Bagnarelli P, Menzo S, Manzin A, Giacca M, Varaldo PE, Clementi M. Detection of human immunodeficiency virus type 1 genomic RNA in plasma samples by reverse-transcription polymerase chain reaction. J Med Virol. 1991 Jun; 34(2): 89-95.

27. Fahey JL, Taylor JMG, Detels R, Hofmann B, Melmed R, Nishanian P, Giorgi JV. The prognostic value of cellular and serologic markers in infection with human immunodeficiency virus type 1. N Engl J Med. 1990 Jan 18; 322(3): 166-72.

28. Garg AB, Nuttall J, Romano J. The future of HIV microbicides: challenges and opportunities. Antiviral Chem Chemother. 2009; 19(4): 143-50.

29. Tolley EE, Harrison PF, Goetghebeur E, Morrow K, Pool R, Taylor D, Tillman SN, van der Straten A. Adherence and its measurement in phase $2 / 3$ microbicide trials. AIDS Behav. 2009 Nov 19. [Epub ahead of print] doi: 10.1007/s10461-009-9635x.

30. Nel AM, Lambert A, Isaacs M, Albertse M, Coetzee L. Daily monitored adherence as a possible adherence enabler in microbicide trials. Microbicides 2010 - Building Bridges in HIV Prevention, Pittsburgh, PA, USA, May 22-25, 2010, Abstract \#58.
31. Schwartz JL, Rountree R, Kashuba A, Brache V, Creinin M, Poindexter A, Kearney, B. A multi-compartment, single and multiple dose pharmacokinetic study of the candidate vaginal microbicide $1 \%$ tenofovir gel. 5 th IAS Conference of HIV, Pathogenesis, Treatemtn and Prevention, Cape Town, South Africa, July 19-22, 2009, Abstract No. LBPEC03.

32. Mayer KH, Maslankowski LA, Gai F, El-Sadr WM, Justman J, Kwiecien A, Mâsse B, Eshleman SH, Hendrix C, Morrow K, Rooney JF, Soto-Torres L; HPTN 050 Protocol Team. Safety and tolerabilityof tenofovir vaginal gel in abstinent and sexually active HIV-infected and uninfected women. AIDS 2006; 20(4): 543-51.

33. Cutler B, Justman J. Vaginal microbicides and the prevention of HIV transmission. Lancet Infect Dis. 2008 Nov; 8(11): 685-97.

34. Creinin MD, Meyn LA, Borgatta L, et al. Multicenter comparison of the contraceptive ring and patch: a randomized controlled trial. Obstet Gynecol 2008; 11(2 Pt 1): 267-277.

35. Lete I, Doval JL, Perez-Campos E, et al. Factors affecting women's selection of a combined hormonal contraceptive method: The TEAM-06 Spanish cross-sectional study. Contraception 2007; 76:77-83.

36. Kamali A. What is new in HIV/AIDS research in developing countries? Trop Med Int Health. 2010 Aug; 15(8): 975-80.

37. Grant RM. Antiretroviral agents used by HIV-uninfected persons for prevention: pre-and postexposure prophylaxis. Clin Infect Dis. 2010 May 15; 50 Suppl 3: S96-101.

38. Underhill K, Operario D, Skeer MR, Mimiaga MJ, Mayer KH. Packaging PrEP to prevent HIV: an integrated framework to plan for pre-exposure prophylaxis implementation in clinical practice. J Acquir Immune Defic Syndr. 2010 Sep 1; 55(1): 8-13.

39. Grant RM, Lama JR, Anderson PL, McMahan V, Liu AY, Vargas L, Goicochea P, Casapía M, Guanira-Carranza JV, Ramirez-Cardich ME, Montoya-Herrera O, Fernández T, Veloso VG, Buchbinder SP, Chariyalertsak S, Schechter M, Bekker LG, Mayer KH, Kallás EG, Amico KR, Mulligan K, Bushman LR, Hance RJ, Ganoza C, Defechereux P, Postle B, Wang F, McConnell JJ, Zheng JH, Lee J, Rooney JF, Jaffe HS, Martinez AI, Burns DN, Glidden DV; the iPrEx Study Team. Preexposure chemoprophylaxis for HIV prevention in men who have sex with men. N Engl J Med. 2010 Nov 23. [Epub ahead of print].

Received: October 1, 2010 / Accepted: November 23, 2010

Address foer correspondence:

Paulina E. Kaptur, PhD

International Partnership for Microbicides

8401 Colesville Road, Suite 200

Silver Spring, MD, USA 20910

Telephone: 1-301-608-2221

Fax: 1-301-608-2241

Email: pkaptur@ipmglobal.org 